\title{
Integrating Qualitative Components in Quantitative Courses Using Facebook
}

\author{
Ashlea Bennett Milburn and \\ Andrew Braham \\ University of Arkansas, \\ Fayetteville, Arkansas, USA \\ ashlea@uark.edu; \\ afbraham@uark.edu
}

\author{
Jeton McClinton \\ Jackson State University, \\ Jackson, Mississippi, USA
}

jeton.mcclinton@jsums.edu

\begin{abstract}
Given Facebook's growing audience among young adults worldwide and the increasing importance of technology, educators are beginning to explore the appropriateness of its use in higher education. The objectives of this paper are to describe the use of Facebook in a transportation logistics course and to compare student perceptions of using Facebook for the stated course purposes to student perceptions of using a more traditional learning management system (LMS). A survey instrument is used to explore how Facebook functionalities compare with those of the Blackboard LMS with respect to ease of use, and to determine how course relationships and communications are impacted when using Facebook instead of Blackboard. Survey results indicate respondents prefer Facebook for functionalities, such as notifications and online discussions, and prefer the Blackboard LMS for functionalities, such as posting lecture notes and grades. Usage of a Facebook group page was associated with higher levels of student-perceived time spent thinking about course materials outside of class, and higher levels of student-perceived connections with other students and with the instructor. Challenges associated with using Facebook instead of the Blackboard LMS included the lack of control over the organization of content in the Facebook group for the course.
\end{abstract}

Keywords: learning management system, Facebook, education, social media, qualitative content, quantitative courses

\section{Introduction}

As of the time of this writing, Facebook is the one of the most popular websites in the United States, second only to Google (Alexa, 2014). Social networks have a large and growing audience

Material published as part of this publication, either on-line or in print, is copyrighted by the Informing Science Institute. Permission to make digital or paper copy of part or all of these works for personal or classroom use is granted without fee provided that the copies are not made or distributed for profit or commercial advantage AND that copies 1) bear this notice in full and 2) give the full citation on the first page. It is permissible to abstract these works so long as credit is given. To copy in all other cases or to republish or to post on a server or to redistribute to lists requires specific permission and payment of a fee. Contact Publisher@InformingScience.org to request redistribution permission. among high-school and college-age Americans. A study conducted by the Pew Research Center in 2010 revealed that $73 \%$ of 12 to 17 year old Americans and $72 \%$ of young American adults are online (Lenhart, Purcell, Smith, \& Zickuhr, 2010). Of American adults age 18 and over with online profiles, $73 \%$ use Facebook, 48\% use Myspace, and 14\% use LinkedIn, revealing that Facebook is the most preferred social net- 
work (Lenhart et al., 2010). Adoption of social networking is high among young adults in other parts of the world too, with the percentage of 18-29 year olds reporting social network use being 94\% in Britain, 84\% in Russia, 62\% in Brazil and 61\% in China (Pew Research Center, 2012). Higher education institutions are learning "that 'technology' rates higher than 'rigor' or 'reputation' in high-school focus groups" when selecting colleges (Bugeja, 2006). Given Facebook's growing audience among young adults worldwide and the increasing importance of technology, educators are beginning to explore the appropriateness of its use in higher education.

While Facebook was designed for social purposes, it has the potential to be used for learning due to the ease with which information in various formats can be shared with a group of people. The Facebook news feed is immediately visible upon logging on and features a list of content updates from a users' friends and groups and pages they follow. Educational content that appears in the Facebook news feed has the opportunity to grab users' attention each time they visit the social media platform. For example, the Institute for Operations Research and the Management Sciences (INFORMS) maintains a Facebook page where it posts links to recent blogs and journal articles from academics and practitioners in the INFORMS community,

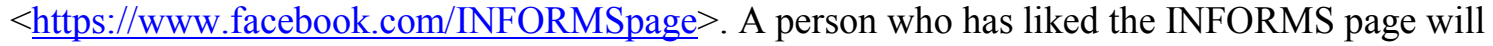
see these links to new results in the field of Operations Research in his or her Facebook news feed. Another example is the Huffington Post, an Internet newspaper that maintains a Facebook page where it shares links to each day's news articles along with short highlights from or commentary for the articles $<$ http://www.facebook.com/HuffingtonPost $>$. People who have liked Huffington Post will see these links in their news feed and can click through to the content most interesting to them, without needing to visit the Huffington Post website separately. A post on the Facebook blog even describes a mechanism for using Facebook to create a personalized news channel (Lucich, 2010). These examples motivate the subject of this paper - how Facebook was incorporated into a college course in transportation logistics. The objectives of this paper are to describe the use of Facebook in a transportation logistics course and to compare student perceptions of using Facebook for the stated course purposes to student perceptions of using more traditional learning management systems. When a Facebook group was created for the course, the instructor posted assignments, course notes, and links to relevant educational content on the web to the group. Then those links appeared in each student's news feed, alongside updates from their friends, each time they logged onto Facebook.

The Facebook news feed brings customized information from various sources to the user in one place. Other services such as Feedly and Google News exist to bring personalized web content to online users. However, Facebook enables users to easily interact with content, posting their own thoughts and opinions on items that are shared. Additionally, Facebook brings this integrated content to a platform users are visiting already. It has been reported that more than $50 \%$ of college students go on Facebook every day (Wang, Woo, Quek, Yang, \& Liu, 2011).

Many institutions of higher education have adopted learning management systems (LMS) that enable the electronic dissemination of course materials and informational content to college students. For example, Blackboard retains the largest LMS market share and their competitors include Moodle, Desire2Learn, and Sakai (Green, 2011). The strengths of such LMS include the ability to organize content and post grades to individual students. These systems also often include a number of other functionalities, for example, blogs, journals, and online discussions. However, students see this content only when they are logged onto the LMS. Social networks have the advantage of bringing the information to where the students already are. Students logging onto Facebook, whether for social purposes or not, can see whether new course materials and educational content are available without needing to leave the site. Meeting the students where they are may have benefits. In fact, one objective of this paper is determining whether us- 
ing Facebook for educational purposes increases the amount of time students spend thinking about course materials outside of class.

There is a growing body of research investigating the use of Facebook in the classroom (e.g., Idris \& Wang, 2009; Muñoz \& Towner, 2009; Roblyer, McDaniel, Webb, Herman, \& Witty, 2010; Schwartz, 2010). A comprehensive review of existing empirical research studies on the use of Facebook for teaching and learning is available in Yang, Wang, Woo, and Quek (2011). A thorough study by Wang et al. (2011) describes the use of Facebook as a LMS in two elective courses and presents the responses to a questionnaire designed to measure student satisfaction with the experience. Key findings indicated students perceived Facebook had been implemented successfully but were divided regarding whether it should be used. While the study provides many helpful insights regarding Facebook use in the classroom, additional research is needed to compare Facebook functionalities to LMS functionalities and to determine how course communications and relationships are impacted when Facebook is used as a LMS. In this paper, we study the following research questions because they have not been fully addressed in the literature at the time of this writing:

1. How do Facebook functionalities compare to LMS functionalities with respect to ease of use?

2. Are students comfortable using Facebook in the college classroom and to communicate with their professors?

3. Can Facebook enhance relationships with course participants and the instructor?

A survey instrument is used to explore the above research questions when using a Facebook group instead of a traditional LMS in a senior-level technical elective course in an undergraduate Industrial Engineering degree program. This paper presents the survey instrument and results.

The course described in this paper provides an introduction to transportation and logistics systems, with a strong emphasis on quantitative models and techniques. Students taking the course develop the ability to analyze costs in logistics systems and formulate decision models for logistics system design and management. In addition to the quantitative content in the course, it is also important for course participants to develop an understanding of business issues in logistics system design and operation. Practical knowledge of the transportation and logistics industry better equips students to successfully bridge the gap between theory and practice and effectively adapt and apply the tools from this course in their future careers. Facebook was selected instead of a LMS for the course because of the dual quantitative and qualitative objectives. While class time focused primarily on quantitative modeling, the Facebook group emphasized online discussions around relevant transportation and logistics articles, videos, and other web content.

The organization of this paper is as follows. The next section describes the implementation of the Facebook group for the course. Then, the research methodology is described in the third section. A questionnaire that was administered to course participants at the end of the semester to gauge student perceptions of the experience is presented. It is also included in the Appendix. Statistical methods used to analyze the response set are noted. The fourth section presents student perceptions as measured by the questionnaire, and then instructor perceptions regarding the successes and challenges associated with Facebook incorporation in the classroom are given in the fifth section. Finally, conclusions and opportunities for future work are discussed in the last sec tion.

\section{Course Implementation}

During a one-semester offering of the introductory transportation logistics course, a Facebook group was created and all enrolled students were asked to join or notify the instructor if they had objections to using the group. No objections were expressed. Online discussions used to support the course objective of developing a practical understanding of issues in logistics systems were 
Integrating Qualitative Components

held in the Facebook group. Course materials, announcements, and assignments were also posted exclusively to the Facebook group. Blackboard, the LMS used by the institution at which this research took place, was used to store and communicate student grades. At the time of this writing, Facebook did not provide a mechanism for securely managing and privately sharing a student grade book. Methods used to ensure privacy, organize content, and encourage online participation in the Facebook group are described below.

\section{Ensuring Privacy}

The privacy of the Facebook group for the course was set to "Closed." This is the middle of three privacy levels available for Facebook groups. While anyone on Facebook can see the group exists and who is in it, they would first need to locate the group by searching for its exact name. Only members of the group can see posts within the group, and the admin (the instructor in this case) was designated as the only person with the authority to approve new members. All members (but only members) were allowed to post to the group. The option to require administrator approval for all posts was not selected.

These group settings ensured that content posted within would not be seen outside the group. However, students were also assured that content posted outside the Facebook group for the course would not be visible within the group. This is an inherent feature of the group mechanism on Facebook. Group members could freely share information on their own profiles and participate in posts originating outside the group without worrying the content would be shared with course participants via the group.

Facebook member profile pictures are available in groups. It was not possible at the time of the course for a Facebook user to designate a different image, other than the profile picture associated with their user account, as the image to represent them in a group. Therefore, students were advised to choose a profile picture they were comfortable with sharing with group members before joining the group. Students were also advised in an initial course meeting how to modify their own personal privacy settings, such that their Facebook content and activity would only be shared with those whom they intended. While information regarding privacy settings is freely available on Facebook, many students remarked that they learned something new during this discussion of Facebook privacy.

Individuals wishing to ensure the utmost degree of privacy when using Facebook for purposes other than social can create a second alternative profile for non-social use. In this way, one account can be designated for sharing photos and news with friends and social circles, and another can be used exclusively to participate in groups for courses and professional societies, for example. However, managing one's Facebook presence in this way requires logging on once to see social news, and separately to see other news. The Facebook news feed will not function as a single unified stream of information with two separate accounts, as it will if all Facebook activity is conducted from a single account. Course participants were advised of this dual-profile option but none selected it.

\section{Organization of Content}

With the exception of discussion threads, content posted within the group was organized into five content areas: small assignments, medium assignments, large assignments, announcements, and course documents. For each of these content areas, a single post was created within the group that included only the text identifying the content area. For example, one post read "Large assignments" and nothing else. Each time a large assignment was given, it was added as a comment to the "Large assignments" post. Most course materials were created and saved as Google Docs using the instructor's Google account, and then a link to the material was included in the 
comment that announced the availability of the material. Occasionally, course materials were created and saved as pdf files or executable files and posted to the instructor's website, because Google Docs did not support these formats. Nonetheless, links to the materials were included in comments that announced the availability of the files.

New discussion topics were added to the group as new posts. Discussion topics always included a link to web content, such as a news article, journal article, or video. Discussion associated with a topic was included in comments for the relevant post.

Facebook sorts content within the group using a newest-first rule. The most recently edited posts or comments appear at the top of the page. Thus, the location of any specific content item within the group feed was dynamic. A particular assignment may have appeared at the top of the feed one day, and several posts down another day.

\section{Encouraging Participation}

For the first several weeks of class, the instructor initiated online discussions within the group. A media item relevant to course objectives would be identified online, and then the instructor would post a link to the item in the group and pose a related thought provoking question. After the instructor had modeled the practice of initiating discussion threads, a rotating weekly schedule was created that designated two to three course participants per week as online discussion leaders. Online discussion leaders were expected to find at least one relevant content item to share with the group along with a link and a specific discussion question regarding the item. Each course participant served as an online discussion leader twice during the semester. When not serving as an online discussion leader, course participants were expected to participate in online discussion threads initiated by their peers at least one to two times per week. An online participation score was assigned for each student and this comprised $5 \%$ of their semester grade.

\section{Methodology}

A questionnaire was designed to collect data at the end of the 16-week semester from course participants regarding their perceptions of various aspects of using Facebook in the course. The full instrument is included in the Appendix. Questionnaire items are grouped into two categories:

1. Comparison of student perceptions when using Facebook and Blackboard for purposes identified in this paper

2. Impact of Facebook on learning and relationships

Blackboard was chosen as the LMS for comparison because it is used at the institution where this study was conducted. All course participants reported past experience with Blackboard in previous courses, so they were qualified to make this comparison.

The comparison of student perceptions when using Facebook and Blackboard was made for nine frequently employed LMS functions: posting grades, posting handouts, posting homework, posting lectures, leading discussions, submitting homework, taking quizzes, updating course calendar, and sending notifications. In category 1 questionnaire items, course participants were asked to rate their perception of the usefulness of, ease of use of, and appreciation for these nine functions. Participants were also asked to rate the convenience of the platforms and express a preference for one of the platforms. All collected data was ordinal.

Two types of hypothesis tests were used to determine whether any statistically significant differences in median responses for the two platforms existed at a level of significance of 0.05 . The Wilcoxon rank-sum test (equivalent to Mann-Whitney U test) was used to test for differences in median response without considering that observations were paired. That is, the full set of responses to a questionnaire item such as "Logging onto Blackboard is convenient" were compared 
Integrating Qualitative Components

to the full set of responses to the questionnaire item "Logging onto Facebook is convenient," without considering that respondent 1 , for example, strongly agreed with the first statement and agreed with the second. It matters only that "strongly agree" is added to the response set for the first item and "agree" is added to the response set for the second item. In contrast, the Wilcoxon signed-rank test was used to test for differences in median response while considering paired observations. In this case, paired data has the potential to explain a portion of the variance in the response set. However, the number of responses to a particular pair of items considered in a Wilcoxon signed-rank test may be less than the number of responses considered in a Wilcoxon ranksum test when respondents provide a response for one item in the pair and leave the other item blank. Thus, the Wilcoxon rank-sum test may be strengthened by larger sample sizes, while the Wilcoxon signed-rank test may be strengthened by paired observations. Results of both types of hypothesis tests are presented for relevant questionnaire items in the Results section.

Category 2 questionnaire items were designed to assess the impact of incorporating Facebook into the course on thinking and relationships. Items solicited participant perceptions of whether incorporating Facebook had increased the amount of time they spent thinking about course material or the ways in which they thought about the material. Participants were also asked whether they perceived stronger connections with other students and the instructor. Response frequency analysis was used to summarize findings.

Instructor experience with designing and managing content and activity within the Facebook group was noted throughout the semester, along with perceived successes and challenges.

\section{Results}

Of the 17 students enrolled in the course, 12 were present in class when the questionnaire was administered. The remaining students were invited via email to participate in the questionnaire. A total of 12 responses were received. The number of responses to each questionnaire item is sometimes less than 12 due to respondents choosing to leave the item blank. No identifying information was collected. Results of the questionnaire are grouped into Category 1 and 2 items as described in the previous section.

\section{Category 1 Questionnaire Items}

For Blackboard and Facebook, participants were asked to rate their perception of the usefulness of, ease of use of, and their appreciation for nine frequently employed LMS functions by rating their agreement with the following statements on a scale of 1 to 5 or leave an item blank if not applicable. Instructions were provided describing 1 to indicate strongly disagree, 2 disagree, 3 neutral, 4 agree, and 5 strongly agree. Each of these statements appeared on the questionnaire twice; once for Blackboard and once for Facebook:

- When I have taken a course utilizing Blackboard [Facebook], the following functionalities were useful to me

- When I have taken a course utilizing Blackboard [Facebook], the following functionalities were easy for me to use

- When I have taken a course utilizing Blackboard [Facebook], I appreciated having the following features be available on the course Blackboard [Facebook] site

For the remainder of this paper, the three statements above will be denoted Usefulness, Ease of Use, and Appreciation, respectively. The median response for each item is summarized in Table 1, where Blackboard is abbreviated B and Facebook is abbreviated F. Results of hypothesis tests are reported, including the number of responses received to the Blackboard item $\left(\mathrm{n}_{1}\right)$, the number of responses received to the Facebook item $\left(\mathrm{n}_{2}\right)$, the $\mathrm{p}$-value of the Wilcoxon rank-sum test $\left(\mathrm{p}^{*}\right)$ and the $\mathrm{p}$-value of the Wilcoxon signed-rank test $\left(\mathrm{p}^{* *}\right)$. Note that the number of paired responses 
considered in each Wilcoxon signed-rank test is the minimum of $n_{1}$ and $n_{2}$. When the $p$-value associated with a hypothesis test is less than 0.05 , the null hypothesis that there is no difference in the medians is rejected in favor of the alternative hypothesis that there is a difference in the medians. P-values given in bold indicate significant differences in median perceptions according to the selected hypothesis test at a level of $\mathbf{0 . 0 5}$ for the stated functionality. Results that are not given in bold indicate the median perceptions of Blackboard and Facebook are not significantly different for the stated functionality at a level of 0.05 .

It should be noted that the comparisons for student perceptions of posting grades, submitting homework and taking quizzes are difficult to interpret. While these functionalities are present in Blackboard and other LMS, they could not be deployed in the Facebook group for the course. It is possible to see in Table 1 that the response rates $\left(\mathrm{n}_{2}\right)$ are lower for the Facebook variants of survey items pertaining to these functions. This is expected, as the option to leave an item blank if not applicable was provided.

Table 1: Median responses and hypothesis test results for platform functionalities

\begin{tabular}{|c|c|c|c|c|c|c|c|c|c|c|}
\hline \multirow[b]{3}{*}{ Item } & \multirow[b]{3}{*}{ Functionality } & \multicolumn{3}{|r|}{ Usefulness } & \multicolumn{3}{|r|}{ Ease of Use } & \multicolumn{3}{|c|}{ Appreciation } \\
\hline & & \multicolumn{2}{|c|}{ Median } & \multirow{2}{*}{$\begin{array}{c}\text { Test results } \\
\mathrm{n}_{1}, \mathrm{n}_{2}, \mathrm{p}^{*}, \mathrm{p}^{* *}\end{array}$} & \multicolumn{2}{|c|}{ Median } & \multirow{2}{*}{$\begin{array}{c}\text { Test results } \\
\mathrm{n}_{1}, \mathrm{n}_{2}, \mathrm{p}^{*}, \mathrm{p}^{* *}\end{array}$} & \multicolumn{2}{|c|}{ Median } & \multirow{2}{*}{$\begin{array}{c}\text { Test results } \\
\mathrm{n}_{1}, \mathrm{n}_{2}, \mathrm{p}^{*}, \mathrm{p}^{* *}\end{array}$} \\
\hline & & $\mathrm{B}$ & $\mathrm{F}$ & & B & $\mathrm{F}$ & & $\mathrm{B}$ & F & \\
\hline A & Posting grades & 5 & 3 & $11,6, \mathbf{0 . 0 0 8}, 0.095$ & 5 & 2 & $10,5, \mathbf{0 . 0 0 5}, 0.174$ & 5 & 4 & $11,5, \mathbf{0 . 0 3 1}, 0.371$ \\
\hline $\mathrm{B}$ & Posting handouts & 5 & 4 & $11,11,0.089,0,168$ & 5 & 4 & $10,10,0.177,0.143$ & 5 & 4 & $11,10, \mathbf{0 . 0 3 2}, 0.053$ \\
\hline $\mathrm{C}$ & Posting homework & 5 & 4 & $11,11,0.063,0.071$ & 5 & 4 & $10,11,0.072,0.188$ & 5 & 4 & $11,10,0.102,0.098$ \\
\hline $\mathrm{D}$ & Posting lectures & 4 & 4 & $11,10,0.433,0.671$ & 4 & 4 & $10,10,0.101,0.202$ & 5 & 4 & $11,10,0.150,0.168$ \\
\hline $\mathrm{E}$ & Leading discussions & 3 & 5 & $11,12, \mathbf{0 . 0 0 0 , 0 . 0 1 4}$ & 3 & 5 & $12,12, \mathbf{0 . 0 0 2 , 0 . 0 1 3}$ & 3 & 4 & $11,12, \mathbf{0 . 0 3 8}, 0.142$ \\
\hline $\mathrm{F}$ & Submitting homework & 4 & 2 & $12,7, \mathbf{0 . 0 3 1}, 0.066$ & 4 & 3 & $12,5, \mathbf{0 . 0 1 2}, 0.053$ & 4 & 3 & $12,5,0.079,0.174$ \\
\hline G & Taking quizzes & 4 & 3 & $12,6,0.126,0.168$ & 4 & 3 & $12,4, \mathbf{0 . 0 1 3}, 0.174$ & 4 & 3 & $11,5,0.311,0.773$ \\
\hline $\mathrm{H}$ & Updating course calendar & 3 & 4 & $10,8, \mathbf{0 . 0 0 5}, \mathbf{0 . 0 4 8}$ & 3 & 4 & $10,7, \mathbf{0 . 0 0 7 , 0 . 0 4 8}$ & 3 & 4 & $11,7, \mathbf{0 . 0 4 3}, 0.053$ \\
\hline I & Sending notifications & 3 & 5 & $11,12, \mathbf{0 . 0 1 2 , 0 . 0 2 8}$ & 3 & 4 & $9,11,0.080,0.288$ & 3 & 4 & $11,12,0.081,0.087$ \\
\hline
\end{tabular}

The median perception of appreciation for the handout posting functionality differs significantly between Blackboard and Facebook, according to the Wilcoxon rank-sum test, with Blackboard receiving a higher median response than Facebook. While Blackboard also received higher median responses for perceptions of usefulness and ease of use of the handout posting functionality than Blackboard, these differences were not significant. Statistically significant differences in median perceptions of usefulness, ease of use, and appreciation for the leading discussions functionality were detected between Blackboard and Facebook, with Facebook receiving higher median responses. Statistically significant differences in median perceptions in usefulness of the course calendar updating and sending notification functionalities were also detected, with Facebook receiving higher median responses for these items. Thus, while student perceptions indicate Blackboard is preferred for functionalities that require file management and storage, they indicate Facebook is preferred for functionalities that foster real-time discussion and provide real-time updates. To summarize, key findings from the results presented in Table 1 include:

- The abilities to post grades, submit homework and take quizzes are available in Blackboard but not in Facebook

- Students found the handout, homework and lecture posting functions more useful and easier to use in Blackboard than in Facebook 
- Students perceived the online discussion, calendar, and notification functions as more useful and easier to use in Facebook than in Blackboard

It should be noted that the comparisons for student perceptions of posting grades, submitting homework and taking quizzes are difficult to interpret. While these functionalities are present in Blackboard and other LMS, they could not be deployed in the Facebook group for the course. It is possible to see in Table 1 that the response rates $\left(\mathrm{n}_{2}\right)$ are lower for the Facebook variants of survey items pertaining to these functions. This is expected, as the option to leave an item blank if not applicable was provided.

The median perception of appreciation for the handout posting functionality differs significantly between Blackboard and Facebook, according to the Wilcoxon rank-sum test, with Blackboard receiving a higher median response than Facebook. While Blackboard also received higher median responses for perceptions of usefulness and ease of use of the handout posting functionality than Blackboard, these differences were not significant. Statistically significant differences in median perceptions of usefulness, ease of use, and appreciation for the leading discussions functionality were detected between Blackboard and Facebook, with Facebook receiving higher median responses. Statistically significant differences in median perceptions in usefulness of the course calendar updating and sending notification functionalities were also detected, with Facebook receiving higher median responses for these items. Thus, while student perceptions indicate Blackboard is preferred for functionalities that require file management and storage, they indicate Facebook is preferred for functionalities that foster real-time discussion and provide real-time updates. To summarize, key findings from the results presented in Table 1 include:

- The abilities to post grades, submit homework and take quizzes are available in Blackboard but not in Facebook

- Students found the handout, homework and lecture posting functions more useful and easier to use in Blackboard than in Facebook

- Students perceived the online discussion, calendar, and notification functions as more useful and easier to use in Facebook than in Blackboard

Questionnaire participants were asked to rate their agreement with the statements included in Table 2 on the same ordinal scale from 1 to 5 (strongly disagree to strongly agree). Each item appeared once for Blackboard and once for Facebook. Median responses for each item are summarized in the table along with p-values for the Wilcoxon rank-sum $\left(\mathrm{p}^{*}\right)$ and Wilcoxon signed-rank $\left(\mathrm{p}^{* *}\right)$ tests. Results in bold indicate significant differences. While the median response for Item $\mathrm{J}$, professor communication platform, indicates a slight preference for Blackboard, the differences are not significant. Conversely, the median response for convenience of logging on indicates a slight preference for Facebook. These differences in medians are also not significant. No difference in convenience of navigation is reported. There is, however, a significant difference in the median responses for convenience of file transfer, with Blackboard being indicated as more convenient when pairing between observations is not considered. To summarize, key findings from the results presented in Table 2 include:

- File transfer is perceived as more convenient using Blackboard than Facebook

- Differences in perceptions of the convenience of logging into and navigating around Blackboard and Facebook are not significant 
Table 2: Median responses and hypothesis test results for convenience and preferences

\begin{tabular}{|l|l|c|c|c|c|c|}
\hline Item & Statement & \multicolumn{2}{|c|}{ Median } & \multicolumn{3}{|c|}{ Test results } \\
\cline { 4 - 7 } & & $\mathrm{B}$ & $\mathrm{F}$ & $\mathrm{n}_{1}, \mathrm{n}_{2}$ & $\mathrm{p}^{*}$ & $\mathrm{p}^{* *}$ \\
\hline $\mathrm{J}$ & $\begin{array}{l}\text { I would prefer to have my professor communicate with } \\
\text { me through Blackboard [Facebook] }\end{array}$ & 4 & 3 & 11,12 & 0.504 & 0.321 \\
\hline $\mathrm{K}$ & Logging onto Blackboard [Facebook] is convenient. & 4 & 5 & 12,12 & 0.298 & 0.301 \\
\hline $\mathrm{L}$ & Navigating around Blackboard [Facebook] is convenient. & 4 & 4 & 12,12 & 0.237 & 0.336 \\
\hline $\mathrm{M}$ & $\begin{array}{l}\text { It is more convenient to transfer files using Blackboard } \\
{[\text { Facebook]. }}\end{array}$ & 4 & 2 & 11,12 & $\mathbf{0 . 0 1 8}$ & 0.081 \\
\hline
\end{tabular}

Two additional questionnaire items asked participants to explicitly compare Facebook and Blackboard by rating their agreement with two statements on a scale of 1 to 5 . The items and statistics summarizing responses are included in Table 3. When asked whether participants were satisfied using Facebook as an alternative to Blackboard, the response median and mode were 3.5 and 4 , respectively, indicating a central tendency to either be neutral toward or agree with the statement. However, the range of responses is high - at least one respondent strongly agreed and at least one respondent strongly disagreed with this statement. The interquartile range is also high at 2.25, indicating a high level of variance in agreement with this statement. Further analysis reveals that the number of responses received of $(1,2,3,4,5)$ are $(3,1,2,5,1)$. Therefore, while 5 participants agree they were satisfied using Facebook and 1 strongly agrees, there were 3 participants that strongly disagree that they were satisfied. Median and mode responses for the statement that Facebook is more effective for delivering online course materials than Blackboard were neutral. There is less variance in response to this item.

Table 3: Summary statistics for explicit comparisons of Blackboard and Facebook

\begin{tabular}{|c|c|c|c|c|c|c|}
\hline Item & Questionnaire item & $\mathrm{n}$ & Median & Mode & Range & $\begin{array}{l}\text { IQ } \\
\text { Range }\end{array}$ \\
\hline $\mathrm{N}$ & $\begin{array}{l}\text { I was satisfied using Facebook as an alternative to } \\
\text { Blackboard }\end{array}$ & 12 & 3.5 & 4 & 4 & 2.25 \\
\hline $\mathrm{O}$ & $\begin{array}{l}\text { Facebook is more effective for delivering online course } \\
\text { materials than Blackboard }\end{array}$ & 12 & 3 & 3 & 3 & 1 \\
\hline
\end{tabular}

\section{Category 2 Questionnaire Items}

Questionnaire items reported in Table 4 were designed to gauge participants' comfort levels with Facebook and measure whether perceived thinking or relationships were impacted. Respondents were asked to rate their agreement with the statements on a scale of 1 to 5 (strongly disagree to strongly agree). As indicated by median and mode responses for Items $\mathrm{P}$ and $\mathrm{T}$, participants agreed they were comfortable using Facebook for online class discussions and with professors using Facebook to communicate for class purposes with students. Median and mode responses for Item Q also indicate participants agreed they liked using Facebook for the class, but the range and interquartile ranges indicated high variance in response to this item. This result is consistent with that of item $\mathrm{N}$ in Table 3. 
Table 4: Median response for student perception of Facebook impact

\begin{tabular}{|c|c|c|c|c|c|c|}
\hline Item & Questionnaire item & $\mathrm{n}$ & Median & Mode & Range & IQ Range \\
\hline $\begin{array}{l}\mathrm{P} \\
\end{array}$ & $\begin{array}{l}\text { I feel comfortable with professors using Facebook to communicate for class } \\
\text { purposes with students. }\end{array}$ & 12 & 4 & 4 & 3 & 1.25 \\
\hline Q & I liked using Facebook for this class. & 12 & 4 & 4 & 4 & 2.25 \\
\hline $\mathrm{R}$ & $\begin{array}{l}\text { Using Facebook for the class increased the time I spent thinking about } \\
\text { Transportation Logistics. }\end{array}$ & 12 & 4 & 4 & 4 & 0.75 \\
\hline S & $\begin{array}{l}\text { Using Facebook for the class made me think of Transportation Logistics in } \\
\text { new or different ways. }\end{array}$ & 12 & 3.5 & 4 & 3 & 1 \\
\hline $\mathrm{T}$ & I feel comfortable using Facebook for online class discussion. & 12 & 4 & 4 & 3 & 1 \\
\hline $\mathrm{U}$ & The quality of instruction in my class improved with Facebook. & 12 & 3 & 3 & 3 & 2 \\
\hline $\mathrm{V}$ & I feel more connected with fellow students in my class using Facebook. & 12 & 4 & 4 & 4 & 2 \\
\hline W & I feel more connected with my instructor using Facebook. & 12 & 4 & 3 & 4 & 2 \\
\hline
\end{tabular}

Responses to items R, S, V, and $\mathrm{W}$ indicate that using Facebook in the class had a positive impact on thinking and relationships. Median and mode responses to items $\mathrm{R}$ and $\mathrm{S}$ indicate agreement that using Facebook increased the time participants spent thinking about transportation logistics and made them think of transportation logistics in new or different ways. This may be explained by the dual-purpose nature of in-class and online discussions. Online discussions focused on qualitative material, which would be "new and different" from the quantitative materials that were the focus of class meetings. Median responses to items $\mathrm{V}$ and $\mathrm{W}$ indicate that participants agreed they became more connected with fellow students and the instructor using Facebook. While these four items taken together indicate a positive impact on thinking and relationships, responses were neutral regarding whether the quality of instruction in the class improved (Item $\mathrm{U})$. This may be because content of online discussions was not regularly integrated with in-class discussions.

Finally, participants were asked to indicate their daily frequency of use of Blackboard and Facebook during the semester in which the course was taken. Response frequencies are summarized in Table 5. In general, Facebook usage was more frequent among course participants than Blackboard usage, with 7 out of 12 participants indicating logging onto Facebook 3 or more times per day, and only 2 out of 12 participants indicating logging onto Blackboard 3 or more times per day. Questionnaire data was inspected to determine whether relationships between usage frequencies and responses to items in Table 4 existed. It was hypothesized that participants using Facebook less frequently would be less likely to report satisfaction with using the platform for the course, but no such relationships were identified.

Table 5: Response frequency of daily use of Blackboard and Facebook

\begin{tabular}{lccccc} 
& \multicolumn{5}{c}{ Times per day } \\
& $<1$ & $1-2$ & $3-4$ & $5-10$ & $>10$ \\
\hline Blackboard & 3 & 7 & 1 & 1 & 0 \\
Facebook & 2 & 3 & 5 & 1 & 1
\end{tabular}

\section{Instructor Perceptions}

Instructor experiences using Facebook as a LMS were noted throughout the semester. The observations contained in this section can be seen as "lessons learned" and should be useful for instructors considering integrating Facebook into their courses. The observations are organized using 
the categories described in the Course Implementation section: ensuring privacy, organization of content, and encouraging participation.

\section{Ensuring Privacy}

Efforts to ensure privacy relied centrally on educating students regarding the specific details of Facebook privacy settings. This instructor highly recommends that educators planning to incorporate Facebook in their courses take the time to familiarize themselves with up-to-date Facebook privacy settings and also teach their students about them. There are many benefits to this approach. First, it can help alleviate students' concerns about privacy, which have been cited as a barrier to Facebook incorporation in the classroom (Muñoz \& Towner, 2009; Roblyer et al., 2010; Wang et al., 2011). Second, it will help students learn how to maintain a professional reputation online. Students may not be aware how accessible the information they share is. While it can be argued they should take responsibility for this themselves, it is a lesson better learned in college than when seeking a career. Third, it will help the instructor be confident that lines between personal and professional are being kept clear. Just as students may worry their information is being shared with the instructor, instructors may have similar concerns over their personal information being shared with the students.

This instructor specifically recommends covering the following privacy topics with participants when using Facebook in a course. Resources for these topics are available on Facebook:

- How to manage accessibility of content posted to one's own profile and elsewhere

- How to create a Limited Profile and manage accessibility to content posted there

- How to manage accessibility to content posted using mobile devices

- How to create and manage an alternate "Instructor" or "Student" account for individuals who would prefer to manage two separate accounts

- Privacy settings selected for the group and how they impact accessibility to information shared within the group

\section{Organization of Content}

According to instructor perception, organization of content was one of the largest barriers to using selected functionalities of Facebook instead of the Blackboard LMS. This perception was shared by the students, as evidenced in questionnaire responses described in the Results section. Additionally, five out of twelve open response comments provided by questionnaire respondents addressed the perceived lack of organization in content in the Facebook group.

The group news feed is dynamic. Therefore, the content that appears at the top of the feed is the post or comment that was most recently added. This feature is helpful in alerting users to what is new, especially for discussion purposes, but it makes it more difficult to find specific items of interest. For example, a student logging on to retrieve a particular assignment may have to search through the news feed for it. After a full semester's worth of file and information sharing, the news feed can become cluttered. While deleting comments would limit the clutter, it would also limit the ability to access and learn from historical content posted there.

As described in the Course Implementation section, assignments and course materials were stored in the instructor's Google Docs accounts or on the instructor's webpage, depending on file type. Google Docs was a convenient mechanism for storing files linked from within the group because when a file was updated, it was not necessary to upload the modified version to the group. File modifications were automatically incorporated in the document on the Google Docs server, so the Facebook link always pointed to the correct file. Since the time of the course offering described in this paper, Facebook has partnered with Dropbox to enable a similar functionality for Facebook groups (Varenhorst, 2012). However, whether using Google Docs or Dropbox, no automat- 
Integrating Qualitative Components

ic group notifications are sent to group members to let them know changes have been made to the file. This is perceived as a weakness.

Since the offering of the course described in this paper, Facebook has also enabled a Files feature for Facebook groups. This feature allows uploading files within a group (Freeman, 2012). The files cannot be music or executable files and must be less than $25 \mathrm{MB}$ in size. All files that are uploaded to the group are available using the Files tab. While this may improve organization, it is still limited in its functionality as a file management system. Files cannot be categorized into folders (e.g., assignments, lectures), and files can only be organized in newest-first fashion.

Events are now available for Facebook groups as well. One option to improve organization of content for Facebook groups is to use events to link categorized content together. For example, an event could be created and designated as "Homework." Then all assignments could be posted to that event as they become available. However, file sharing is not currently enabled within events. A file sharing mechanism such as posting links to files stored within Google Docs would need to be used.

\section{Encouraging Participation}

Course participants were asked at the beginning of the semester to notify the instructor if they would have objections to using Facebook instead of a LMS for the course. Because no objections were received, the study using Facebook as an alternative to a LMS could take place. Once the Facebook group was created, participation was encouraged by stating expectations in terms of average weekly frequency of posts and comments to the group. Course participants were also scheduled to lead discussions twice during the course of the semester. Because these expectations were made clear, it is not possible to determine whether participation would have organically evolved within the group without expectations being set.

Online discussions were only occasionally integrated into in-class discussions. It was perceived by the instructor that highlighting online content during class more frequently would encourage higher levels of both in-class and online participation, and would better integrate the qualitative and quantitative objectives of the course. It was also perceived by the instructor that higher levels of instructor involvement in the Facebook group led to higher levels of student involvement in the group.

\section{Conclusions}

There were both challenges and benefits to using Facebook for select functionalities of a learning management system (LMS) in the senior-level industrial engineering technical elective in transportation logistics. Benefits included higher levels of student-perceived time spent thinking about course materials outside of class, and higher levels of student-perceived connections with other students and with the instructor. Challenges included the lack of control over the organization of content in the group.

Ultimately, the perceived strengths of Facebook and Blackboard with respect to the purposes identified in this paper were closely related to each platform's core competencies. Facebook, which is designed for social engagement, was perceived as easier to use than Blackboard for leading discussions and sending notifications. Blackboard, designed as a learning management system, was perceived as easier to use than Facebook for posting files and homework. Additionally, Blackboard was preferred for posting grades because this functionality was not available on Facebook. Open responses received to the final questionnaire item summarize these strengths and weaknesses well: 
- "Facebook is much better for discussion, but horrible when it comes to file sharing."

- "Facebook is better except at posting grades. Blackboard allows easy access to grades."

- "It would be nice if there were a way to view grades using Facebook. That's the only thing I missed about Blackboard. It was easier to keep up with what was happening in the course because I log onto Facebook for social purposes and get reminded that I have an assignment due or that there's something I need for class that day."

Open responses provided by course participants in the questionnaire indicated frustration with the perceived lack of organization of content on Facebook. For example, one participant indicated a complaint against Facebook as "files are scattered down the post wall". Another student described their experience in this way: "The Facebook page for our class was hard to navigate because the assignments, documents, and announcements were always out of view on my screen. I had to scroll down, sometimes multiple times (if I didn't see it the first time) to find what I was looking for." Participants also expressed that, because they were taking other courses that were using Blackboard, it would be nice to have all of their courses catalogued in one place. When asked whether they would hypothetically prefer all courses to be catalogued on Blackboard or Facebook, 8 respondents indicated a preference for Blackboard and 4 indicated a preference for Facebook.

The results presented in this paper represent only one institution and discipline. It would be interesting to see whether student perceptions of Facebook use in the classroom differ based on independent variables such as gender, geographic location, reputation and size of university, and academic discipline. Instructors that are currently using Facebook in their college courses are encouraged to publish their experiences to enable these types of comparisons. As more information becomes available, perhaps faculty reluctance, which has been stated as a major barrier to effective integration of technology in education, will dissipate (Roblyer et al., 2010). Facebook continues to add mechanisms that have potential to improve its functionality as a LMS (e.g., files tab, academic groups). As some of the described challenges are overcome by these developments, use of Facebook as a LMS is expected to improve. Future research should continue to monitor these changes and measure student and faculty perceptions of Facebook incorporation in the classroom.

\section{References}

Alexa. (2014). Top sites in United States. Retrieved from http://www.alexa.com/topsites/countries/US

Bugeja, M. J. (2006). Facing the Facebook. Chronicle of Higher Education, 52(21), C1-C4.

Freeman, K. (2012). Facebook rolls out file-sharing for all groups [Web log comment]. Retrieved from http://mashable.com/2012/05/10/facebook-groups-3/

Green, K. C. (2011). Campus computing: Big gains in going mobile. Retrieved from http://www.campuscomputing.net/item/campus-computing-2011-big-gains-going-mobile

Idris, Y., \& Wang, Q. Y. (2009). Affordances of Facebook for learning. International Journal of Continuing Engineering Education and Life-Long Learning, 19(2/3), 247-255.

Lenhart, A., Purcell, K., Smith, A., \& Zickuhr, K. (2010). Social media and young adults. Pew Internet \& American Life Project. Retrieved from http://www.pewinternet.org/Reports/2010/Social-Media-andYoung-Adults.aspx

Lucich, M. (2010). Creating your personalized news channel [Web log comment]. Retrieved from http://blog.facebook.com/blog.php?post $=276507062130$

Muñoz, C. L., \& Towner, T. L. (2009). Opening Facebook: How to use Facebook in the college classroom. Proceedings from AACE '09: Society for Information Technology Teacher Education International Conference. Chesapeake, VA, 2623-2627. 
Integrating Qualitative Components

Pew Research Center. (2012). Social network popular across globe. Pew Global Attitudes Project. Retrieved from http://www.pewglobal.org/2012/12/12/social-networking-popular-across-globe/

Roblyer, M. D., McDaniel, M., Webb, M., Herman, J., \& Witty, J. V. (2010). Findings of Facebook in higher education: A comparison of college faculty and student uses and perceptions of social networking sites. Internet and Higher Education, 13, 134-140.

Schwartz, H. L. (2010). Facebook: The new classroom commons?. The Chronicle Review, 75(5), 39-42.

Varenhorst, C. (2012). Share stuff from Dropbox in your Facebook groups [Web log comment]. Retrieved from https://blog.dropbox.com/2012/09/share-stuff-from-dropbox-in-your-facebook-groups/

Wang, Q., Woo, H. L., Quek, C. L., Yang, Y., \& Liu, M. (2011). Using the Facebook group as a learning management system: An exploratory study. British Journal of Educational Technology, 43(3), 428438.

Yang, Y., Wang, Q., Woo, H.L., \& Quek, C.L. (2011). Using Facebook for teaching and learning: A review of the literature. International Journal of Continuing Engineering Education and Life-Long Learning, 21(1), 72-86.

\section{Appendix}

1. When I have taken a course utilizing Blackboard, the following functionalities were useful to me (please check one box per functionality; leave blank if not applicable):

\begin{tabular}{|r|r|l|l|l|l|}
\hline & $\begin{array}{c}\text { Strongly } \\
\text { Disagree }\end{array}$ & Disagree & Neutral & Agree & $\begin{array}{c}\text { Strongly } \\
\text { Agree }\end{array}$ \\
\hline Posting grades & & & & & \\
\hline Posting handouts & & & & & \\
\hline Posting homework & & & & & \\
\hline Posting lectures & & & & & \\
\hline Submitting homework & & & & & \\
\hline Taking quizzes & & & & & \\
\hline $\begin{array}{r}\text { Updating course calen- } \\
\text { dar }\end{array}$ & & & & & \\
\hline Sending notifications & & & & & \\
\hline
\end{tabular}

2. When I have taken a course utilizing Blackboard, the following functionalities were easy to use for me (please check one box per functionality; leave blank if not applicable):

\begin{tabular}{|r|r|l|l|l|l|}
\hline & $\begin{array}{c}\text { Strongly } \\
\text { Disagree }\end{array}$ & Disagree & Neutral & Agree & $\begin{array}{c}\text { Strongly } \\
\text { Agree }\end{array}$ \\
\hline Posting grades & & & & & \\
\hline Posting handouts & & & & & \\
\hline Posting homework & & & & & \\
\hline Posting lectures & & & & & \\
\hline Submitting homework & & & & & \\
\hline Taking quizzes & & & & & \\
\hline $\begin{array}{r}\text { Updating course calen- } \\
\text { dar }\end{array}$ & & & & & \\
\hline Sending notifications & & & & & \\
\hline
\end{tabular}


3. When I have taken a course utilizing Blackboard, I appreciated having the following features be available on the course Blackboard page (please check one box per functionality; leave blank if not applicable):

\begin{tabular}{|r|r|l|l|l|l|}
\hline & $\begin{array}{c}\text { Strongly } \\
\text { Disagree }\end{array}$ & Disagree & Neutral & Agree & $\begin{array}{c}\text { Strongly } \\
\text { Agree }\end{array}$ \\
\hline Posting grades & & & & & \\
\hline Posting handouts & & & & & \\
\hline Posting homework & & & & & \\
\hline Posting lectures & & & & & \\
\hline Leading discussions & & & & & \\
\hline $\begin{array}{r}\text { Submitting homework } \\
\text { Taking quizzes }\end{array}$ & & & & \\
\hline Sending course calen- & & & & & \\
\hline
\end{tabular}

4. When I have taken a course utilizing Facebook, the following functionalities were useful to me (please check one box per functionality; leave blank if not applicable):

\begin{tabular}{|r|r|l|l|l|l|}
\hline & $\begin{array}{c}\text { Strongly } \\
\text { Disagree }\end{array}$ & Disagree & Neutral & Agree & $\begin{array}{c}\text { Strongly } \\
\text { Agree }\end{array}$ \\
\hline Posting grades & & & & & \\
\hline Posting handouts & & & & & \\
\hline Posting homework & & & & & \\
\hline Posting lectures & & & & & \\
\hline Leading discussions & & & & & \\
\hline Submitting homework & & & & & \\
\hline Taking quizzes & & & & & \\
\hline Sendating course calen- & & & & & \\
\hline
\end{tabular}

5. When I have taken a course utilizing Facebook, the following functionalities were easy to use for me (please check one box per functionality; leave blank if not applicable):

\begin{tabular}{|r|r|l|l|l|l|}
\hline & $\begin{array}{c}\text { Strongly } \\
\text { Disagree }\end{array}$ & Disagree & Neutral & Agree & $\begin{array}{c}\text { Strongly } \\
\text { Agree }\end{array}$ \\
\hline Posting grades & & & & & \\
\hline Posting handouts & & & & & \\
\hline Posting homework & & & & & \\
\hline Posting lectures & & & & & \\
\hline Submitting homework & & & & & \\
\hline Taking quizzes & & & & & \\
\hline $\begin{array}{r}\text { Updating course calen- } \\
\text { dar }\end{array}$ & & & & & \\
\hline Sending notifications & & & & & \\
\hline
\end{tabular}


6. When I have taken a course utilizing Facebook, I appreciated having the following features be available on the course Facebook page (please check one box per functionality; leave blank if not applicable):

\begin{tabular}{|r|r|l|l|l|l|}
\hline & $\begin{array}{c}\text { Strongly } \\
\text { Disagree }\end{array}$ & Disagree & Neutral & Agree & $\begin{array}{c}\text { Strongly } \\
\text { Agree }\end{array}$ \\
\hline Posting grades & & & & & \\
\hline Posting handouts & & & & & \\
\hline Posting homework & & & & & \\
\hline Posting lectures & & & & & \\
\hline Submitting homework & & & & & \\
\hline Taking quizzes & & & & & \\
\hline $\begin{array}{r}\text { Updating course calen- } \\
\text { dar }\end{array}$ & & & & & \\
\hline Sending notifications & & & & & \\
\hline
\end{tabular}

7. Please read each statement and check one box per statement.

\begin{tabular}{|c|c|c|c|c|c|}
\hline & $\begin{array}{l}\text { Strongly } \\
\text { Disagree }\end{array}$ & Disagree & Neutral & Agree & $\begin{array}{l}\text { Strongly } \\
\text { Agree }\end{array}$ \\
\hline \multicolumn{6}{|l|}{ Communications with Professor } \\
\hline \multicolumn{6}{|l|}{$\begin{array}{l}\text { I would prefer to have my professor } \\
\text { communicate with me through Fa- } \\
\text { cebook. }\end{array}$} \\
\hline \multicolumn{6}{|l|}{$\begin{array}{l}\text { I would prefer to have my professor } \\
\text { communicate with me through } \\
\text { LinkedIn. }\end{array}$} \\
\hline \multicolumn{6}{|l|}{$\begin{array}{l}\text { I would prefer to have my professor } \\
\text { communicate with me through } \\
\text { Blackboard. }\end{array}$} \\
\hline \multicolumn{6}{|l|}{ Blackboard } \\
\hline \multicolumn{6}{|l|}{$\begin{array}{l}\text { Logging onto Blackboard is con- } \\
\text { venient. }\end{array}$} \\
\hline \multicolumn{6}{|l|}{$\begin{array}{l}\text { Navigating around Blackboard is } \\
\text { convenient. }\end{array}$} \\
\hline \multicolumn{6}{|l|}{ Facebook } \\
\hline \multicolumn{6}{|l|}{$\begin{array}{l}\text { I feel comfortable with professors } \\
\text { using Facebook to communicate for } \\
\text { class purposes with students. }\end{array}$} \\
\hline \multicolumn{6}{|l|}{$\begin{array}{l}\text { Logging onto Facebook is conven- } \\
\text { ient. }\end{array}$} \\
\hline \multicolumn{6}{|l|}{$\begin{array}{l}\text { Navigating around Facebook is } \\
\text { convenient. }\end{array}$} \\
\hline \multicolumn{6}{|l|}{$\begin{array}{l}\text { It is more convenient to transfer } \\
\text { files using Facebook. }\end{array}$} \\
\hline $\begin{array}{l}\text { It is more convenient to transfer } \\
\text { files using LinkedIn. }\end{array}$ & & & & & \\
\hline
\end{tabular}




\begin{tabular}{|l|l|l|l|l|l|}
\hline & $\begin{array}{c}\text { Strongly } \\
\text { Disagree }\end{array}$ & Disagree & Neutral & Agree & $\begin{array}{c}\text { Strongly } \\
\text { Agree }\end{array}$ \\
\hline $\begin{array}{l}\text { It is more convenient to transfer } \\
\text { files using Blackboard. }\end{array}$ & & & & & \\
\hline Experience & & & & \\
\hline $\begin{array}{l}\text { I liked using Facebook for INEG } \\
4633 .\end{array}$ & & & & \\
\hline $\begin{array}{l}\text { Using Facebook for the class in- } \\
\text { creased the amount of time I spent } \\
\text { thinking about Transportation Lo- } \\
\text { gistics. }\end{array}$ & & & & & \\
\hline $\begin{array}{l}\text { Using Facebook for the class made } \\
\text { me think of Transportation Logis- } \\
\text { tics in new or different ways. }\end{array}$ & & & & & \\
\hline $\begin{array}{l}\text { I feel comfortable using Facebook } \\
\text { for online class discussion. }\end{array}$ & & & & & \\
\hline $\begin{array}{l}\text { I was satisfied using Facebook as } \\
\text { an alternative to Blackboard. }\end{array}$ & & & & & \\
\hline $\begin{array}{l}\text { Facebook is more effective for de- } \\
\text { livering online course materials } \\
\text { than Blackboard. }\end{array}$ & & & & & \\
\hline $\begin{array}{l}\text { The quality of instruction in my } \\
\text { class improved with Facebook. }\end{array}$ & & & & & \\
\hline $\begin{array}{l}\text { I feel more connected with fellow } \\
\text { students in my class using Face- } \\
\text { book. }\end{array}$ & & & & & \\
\hline $\begin{array}{l}\text { I feel more connected with my in- } \\
\text { structor using Facebook. }\end{array}$ & & & & & \\
\hline
\end{tabular}

8. Please fill out the following table checking one box per statement.

\begin{tabular}{|l|l|l|l|l|l|}
\hline $\begin{array}{l}\text { During the current aca- } \\
\text { demic semester, my } \\
\text { frequency of use of Fa- } \\
\text { cebook has been ap- } \\
\text { proximately: }\end{array}$ & $\begin{array}{c}5 \text { to } 9 \\
\text { times/day }\end{array}$ & $\begin{array}{c}3 \text { to } 4 \\
\text { times/day }\end{array}$ & $\begin{array}{c}1 \text { to 2 } \\
\text { times/day }\end{array}$ & $\begin{array}{c}\text { Less than } \\
\text { once/day }\end{array}$ \\
\hline $\begin{array}{l}\text { During the current aca- } \\
\text { demic semester, my } \\
\text { frequency of use of } \\
\text { LinkedIn has been ap- } \\
\text { proximately: }\end{array}$ & & & & & \\
\hline $\begin{array}{l}\text { When I have taken a } \\
\text { course utilizing Black- } \\
\text { board, my frequency of } \\
\text { use of Blackboard has } \\
\text { been approximately: }\end{array}$ & & & & & \\
\hline
\end{tabular}


9. Assume the following three choices are available and that, in all three cases, all of your courses are catalogued in one place. Select the choice you prefer:

a. All of my professors use Blackboard for class.

b. All of my professors use Facebook for class.

c. All of my professors use LinkedIn for class.

10. Please feel free to comment below on any other perspective of using Facebook in the classroom.

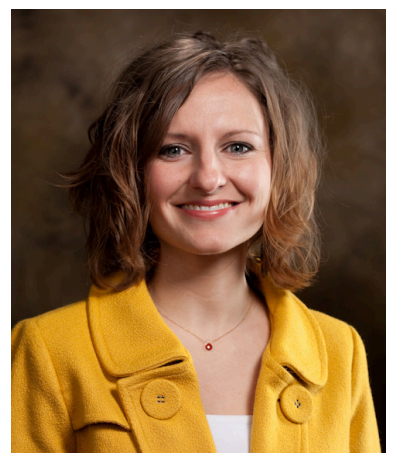

\section{Biographies}

Dr. Ashlea Bennett Milburn joined the faculty of the Department of Industrial Engineering at the University of Arkansas in January 2010 as an Assistant Professor. She received a Ph.D. in Industrial and Systems Engineering from Georgia Tech, a M.S in Industrial Engineering from Virginia Tech, and a B.S.from the University of Arkansas. Her primary areas of teaching and research are Transportation Logistics and Healthcare Systems Engineering. Dr. Milburn enjoys applying operations research tools and techniques to large-scale problems arising in the healthcare and logistics industries. More specifically, much of her research has focused on logistics planning problems encountered in home health care and disaster relief.

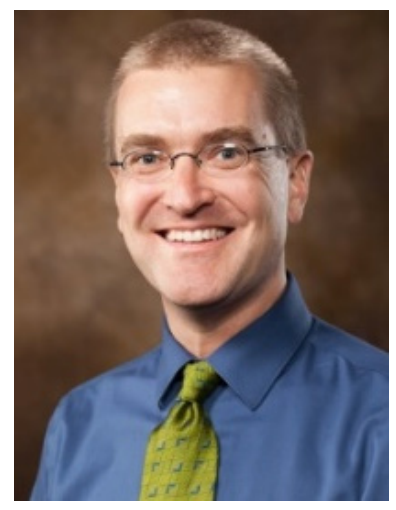

Dr. Andrew Braham is an Assistant Professor in the Department of Civil Engineering at the University of Arkansas. He holds a Ph.D. from the University of Illinois and B.S.and M.S. degrees from the University of Wisconsin. His industry experience includes two years with Koch Materials Company. Prior to joining the faculty at the University of Arkansas in 2010, Dr. Braham served as a Post-Doctoral Research Fellow at Southeast University in Nanjing, China. As a faculty member, his research focuses on transportation materials and sustainability. A major component of Dr. Braham's laboratory deals with pavement maintenance and rehabilitation products and advanced pavement materials characterization.

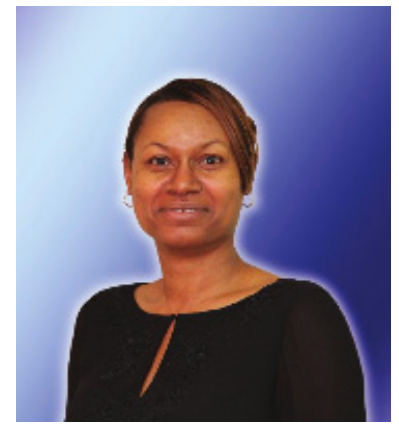

Dr. Jeton McClinton is a faculty member at Jackson State University where she teaches educational leadership and technology courses in the Department of Educational Leadership. She received a B.A. from Washington State University, an M.Ed. from the George Washington University and a Ph.D. from Mississippi State University. She has presented and authored on technology integration in the curriculum at a variety of local, regional, national and international conferences. Her research interests include faculty professional development, social networking, virtual learning communities, and student learning styles in electronic courses. 